\title{
The VLE versus Open Education
}

\author{
Angelica Risquez, University of Limerick \\ Claire McAvinia, Dublin Institute of Technology
}

\begin{abstract}
In this paper we consider the position of the VLE in the context of the open education movement. This paper gathers data from the \#VLEIreland survey in order to explore further whether open education was a concern of the academics involved, and if so, how it shaped their use of the local VLE. We will explore the nature of open education and open educational resources (OER), and whether there are interactions between these resources and the VLE. Open educational resources are materials shared online for educators to use and adapt, including full courses, modules, textbooks, and assets such as video clips, images or teaching methods. Data from our staff survey indicates a range of responses to the sharing and use of OERs and a spectrum of understanding (or lack of understanding) of copyright issues. We explore these findings and discuss their implications for OER in the future, and suggest that the ideals of "openness" are challenged by institutional VLEs and other mechanisms for resource sharing in higher education.
\end{abstract}

\section{Introduction}

Over the past decade or so the open education movement has continued to gather momentum in higher education, spurred on by increasing demand for more flexible education options; by the potential of developments in technology and infrastructure; by advocacy at policy level; and by initiatives and developments at national and international levels. The term 'Open Educational Resource' has been formally defined as:

[t]he open provision of educational resources, enabled by information and communication technologies, for consultation, use and adaptation by a community of users for non-commercial purposes (UNESCO, 2002, p. 24)

Open educational resources (OER) and massive open online courses (MOOCs), two of the elements of the open education movement, have seen exponential growth and public debate in this period. However, navigating this landscape poses a number of important issues and questions for the practice of teaching and learning. From an educational development perspective, the focus rests on investigating how both students and teachers can use and engage with open education in ways that optimally enhance teaching and learning. There is a wealth of data and literature from research, projects and initiatives on open education at international level that can provide some guidance.

Irish Journal of Technology Enhanced Learning Ireland, 2018. () 2018 Risquez, A. \& McAvinia, C. The Irish Journal of Technology Enhanced Learning Ireland is the journal of the Irish Learning Technology Association, an Irish-based professional and scholarly society and membership organisation. (CRO\# 520231) http://www.ilta.ie/. This is an Open Access article distributed under the terms of the Creative Commons Attribution 4.0 International License (http://creativecommons.org/licenses/by/4.0), allowing third parties to copy and redistribute the material in any medium or format and to remix, transform, and build upon the material for any purpose, even commercially, provided the original work is properly cited and states its license. 
In Ireland too there have been a number of initiatives that we can learn from and build upon, particularly in relation to the use of digital repositories of OER. Furthermore, there are policy contexts at international, European and Irish levels that provide a backdrop to our understanding of the issue. As a starting point, the definition of OER should provide some insight. There are many, often contested, definitions of OER, but most authors recognize them as "teaching, learning and research resources that reside in the public domain or have been released under an intellectual property license that permits their free use and repurposing by others. Unlike traditionally copyrighted material, these resources are available for 'open' use, which means users can edit, modify, customize, and share them" (Babson Survey Research Group, 2014, p.9). The spectrum of OER can range from complete courses to a single image. There are, obviously, different approaches and motivations behind say MIT open courseware and a diagram developed to support a concept by an individual lecturer. Martin Weller (2009) makes a useful distinction (attributing Michelle Hoyle) between 'big OER' and 'little OER' as 'top-down' and 'bottom-up' OER respectively. The big headlinegrabbing digital 'story' in recent years around MOOCs as examples of 'big OER' has muddied the waters somewhat in relation to the 'open' project, leading to despondency among originators about the reinterpretation of 'open' as 'free' or 'online' without some of the 'reuse' possibilities originally envisaged (Weller, 2014). However, in the context of the enhancement of teaching and learning and the potential of OER to shift teaching and learning practice in the direction of openness, little OER could be considered to be more relevant. As Weller (2009) states:

[Higher Education] institutions are implementing big OER projects to release their traditional material, whereas individual academics are creating new types of content.

That is not to say that 'big OER' are irrelevant. For example, there may be some 'big OER' that can be taken apart and broken down into their constituents and they can add significantly to the supply of 'little OER' for reuse. They may also be relevant in some of the other ways academics use OER, e.g. benchmarking practice, or getting ideas for developing modules. It is at this level that the VLE probably has a strong role to play, as a vehicle for curation, repurposing and dissemination of such resources that is familiar and easily accessible to the average teacher.

Resulting from the specific strategic recommendations included on its National Digital Roadmap (2014), the National Forum for the Enhancement of Teaching and Learning commissioned in 2015 a focused research project to examine how open educational resources can be utilised, developed and shared in order to enhance teaching and learning in Irish higher education (Risquez et al., 2015). This piece of research demonstrated that there was still a poor understanding of the term "open educational resource" amongst many academics. While there had been a strong level of awareness-raising during the lifespan of the National Digital Learning Repository project ${ }^{1}$, the research indicated that a similar mission of awareness-raising and training would be needed to foster greater use of OER amongst academic staff teaching in third level in Ireland in the future. In a survey with 192 academics, less than half of respondents reported being aware of OER. It is also arguable that the survey respondents were overall those most interested in OER and/or most motivated to respond, given the self-selective nature of the research. When combined with the poor understanding of OER that emerged in responses to open questions, it could be speculated that real awareness levels are considerably lower. The use of OER as supplementary course material

${ }^{1}$ https://www.teachingandlearning.ie/ndlr/ 
outweighed use as primary course material. Respondents reported that the most important deterrents to the use of OER in their courses were quality, time to search for relevant and usable resources, and the lack of relevant materials. Respondents were most aware of copyright licensing (68\% 'aware' or 'very aware'), while over half of respondents were unaware, or just somewhat aware, of creative commons and public domain licensing. When reusing OER, just over a quarter of respondents declared to take copyright issues into consideration. While almost two-thirds of respondents stated that they 'shared' resources, when they were asked to specify how they shared, answers revealed that this occurs privately, for the most part, between colleagues. Sharing resources with students, either through course delivery or VLEs, was also put forward as an example of how respondents shared their educational resources. A series of focus groups across institutions participating in the project confirmed that online repositories were often confused with VLEs in their discussion of such resources. Therefore in the current research, it was important to gather data that could explore further whether open education was a concern of the academics involved, and if so, how it shaped their use of the local VLE.

\section{Data and analysis}

The findings presented in this chapter are drawn predominantly from qualitative responses to Questions 15 and 16a of the questionnaire for staff participating in the \#VLEIreland research, which has been extensively presented in the initial papers in this issue (Harding, 2018; Farrelly, Raftery \& Harding, 2018). Data were collected between autumn 2014 and spring 2015 in seven of the participating institutions. Question 15 asked staff how they dealt with copyright issues for digital learning objects that they reused. There were 303 responses to this question. Question 16a asked staff to comment on how they shared digital learning resources they produced themselves. There were 178 answers to this question. In both cases answers were brief (no more than a few words) and were coded manually. In the analysis presented in here, we compare this data with other findings from the survey and use this comparison to gain insights into the attitudes of staff towards sharing, using and reusing digital learning resources.

\subsection{Staff Survey: using and sharing of OERs}

When asked to comment on how they currently shared the digital learning resources that they produced, responses quickly showed that this was interpreted as inclusive of everyday mainstreamed practices such as using the VLE and email, rather than a broader concept of sharing resources to professional networks, through public websites of any kind, or through online educational repositories:

upload, file transfer by memory stick, email, cloud (depends on size of file)

email to colleagues

give copies of my material to my colleagues via email/memory stick

31 responses referred to sharing via the VLE and 26 to sharing via email. 29 people referred to giving resources directly to colleagues but did not specify how they did this or whether the format used was digital or not.

make them available to other lecturers in my area, if they want them

I share them with colleagues 
Eight people referred to sharing via the now-defunct NDLR (www.ndlr.ie) and a further eight shared via Twitter (www.twitter.com). Six people shared resources on YouTube. Other solutions included using USB keys (five people), filesharing on local networks (five) and using Slidehare (four).

often via social media or email

Either via a personal website, email or moreso now via social media. Esp Twitter.

The remaining responses were from fewer than five people each but indicated wide-ranging ways of sharing materials including PowerPoint, personal websites or blogs, Github, Vimeo, local websites, Facebook, cloud applications, and giving links to students in class. Nondigital sharing was also reflected, including use of paper handouts, video material, and paper books:

lending students my resources - books and videos

copy them for colleagues

hand them to colleagues or email

Elsewhere in the questionnaire, staff had been asked to comment on any reasons why they did not use the VLE and in this question some expressed concerns about the loss of their intellectual property, for example:

if you put a lot of work into creating good notes etc. for a particular module and then you are no longer asked to lecture that module, the following lecture[r] will get the benefit of all your work

This finding, taken in conjunction with the interpretation of 'sharing' as being via the VLE for a majority of respondents, indicates that although academics may subscribe to the philosophy of openness and the sharing of educational resources, many of them will only share their own materials via the VLE. This in effect renders such resources closed since most VLEs are password-protected spaces restricted to use by staff and students at particular institutions. Similarly, sharing through many of the other methods cited implied restricted access to resources e.g. sharing via email, distributing links in lectures, PowerPoint files, transfer on USB key and so on. Although sites such as Facebook, Slideshare and others are potentially open access to any user, they can also be used in 'closed' ways through restricting access to groups, invited users, friends or followers. Cloud applications are not necessarily used in an 'open' fashion by staff either. Answers indicating use of these mechanisms cannot be interpreted as meaning that someone is publicly or openly sharing resources. Further research would be needed to establish sharing practices in these spaces.

\subsection{Copyright in the VLE}

Question 15 of our staff survey asked how staff dealt with copyright issues for digital learning objects that they reused. Overall, the data indicated that most staff using a VLE were not engaging with copyright issues at all, either because they had not considered copyright at any level or because they perceived the VLE as being protected and safe even though it is web-based. 
77 responses indicated that staff used references to secondary sources on handouts or PowerPoint slides as a means of addressing copyright and use of these materials:

acknowledge the source, reference within notes, name the author

Cite sources

I reference all the material I use

While there is good practice here to some extent, references do not address the sharing or transmission onwards to students of particular resources. This suggests that there is an incomplete understanding of copyright in terms of the sharing on of resources and other materials via the VLE or indeed via other mechanisms. 44 people commented that they would "acknowledge sources" in some way. However, 42 respondents said they did not deal with copyright at all or that they did not think about it, with the following responses being typical:

I don't worry about copyright

Assume acceptable usage levels for education

Do not think much about it

I assume that if they are available without restriction on Google that they are intended for sharing. I always cite the source to be sure

16 responses referred to relying on 'fair use' for educational purposes and another 18 responses referred to including links on teaching materials to address copyright. Interestingly, 20 people marked this question as 'N.A' or 'not applicable'. It is difficult to interpret this data: we cannot be sure from these replies whether the question was genuinely not applicable to their work or whether they regarded it as not applicable. 10 responses consisted of the query symbol "?" entered one or more times to the text box. 17 responses indicated that people "ignored" copyright issues and a further 19 said they did not know the rules:

head in the sand

I have little or no knowledge of copyright issues

I believe there is a system for this in [institution], however I must admit I have been lax in this area

I would welcome institutional guidance about this

In spite of this confusion around copyright there was evidence of some better practice in the data. 16 people reported using Creative Commons materials and a further 16 responses mentioned asking for permission to use material:

Use Creative Commons where possible

I'm scrupulous about copyright issues. For images, I always look for CC-licences. When in doubt I use tin-eye to find the oldest version of the image. For text, I link to open source/licensed content.

People commented on seeking OER (six), using Open Source material (six), using resources for which Libraries had subscriptions (five), licensed material from publishers (four), or material which was out of copyright (four). 
A mix of other practices was reported by small numbers of individuals (fewer than three). These included consulting librarians, using YouTube, using materials within the lecture only and not in the VLE, using "very little" copyright material, requesting the provision of additional e-books by Library, restricting access via the VLE, and altering materials before using them. Responses included such phrases as "hope for the best", and "major ethical concern" again indicating some awareness of the importance of copyright but also confusion and some improvisation around this issue.

\section{Discussion: VLE versus open education?}

In our research with staff, we have found confusion around what OER are and how they should be used and shared. We also found wider concerns around sharing for a range of reasons. These findings were also reflected in the focused research project undertaken for the National Forum in Ireland (Risquez et al., 2015). The VLE is regarded as a reasonably safe space but even here there are constraints on how materials are shared, and some staff opt not to share via the VLE at all because of such concerns. Only half of the staff participating in the survey shared their teaching materials, and this was through the VLE rather than in an open fashion. The other sharing mechanisms cited were not necessarily being used in an open way: it is possible that academics sharing in the protected spaces of the VLE are also protecting and closing other spaces in which they share materials with a select group of colleagues and/or students. This may be based on fears around intellectual property and the loss of their work, or simply to provide protected spaces in order to manage students' data and assessed work. It is possible that their nagging doubts about copyright mean they think that closing spaces will protect them from complaints (or worse) if they have not adhered to best practice in the use of third party materials. Alternatively, some academics may have created their own alternatives to the institutional VLE using other sites (for example, Google Classroom has been used for this purpose within our own institutions) and manage these sites in the same restricted fashion that they would manage a VLE space. So, while the VLE may be critiqued as a closed system, so are most of the alternatives that academics are using. The bigger question here might be why so many cultural problems remain with buying into the open education movement and the use of OER.

From this research we are bound to ask whether copyright confusion is the cause or effect of a lack of engagement with OER use. The data, albeit subject to the constraints of the size of our dataset and the methodological approach to collection, indicates widespread confusion and ignorance about copyright, confirming findings at national level (Risquez et al., 2015). Restricting the sharing of resources could be part of this confusion, or alternatively it is incidental if academics are not interested in sharing their resources in the first place. In this vein, the metaphor of an iceberg is used by White and Manton $(2011$, p. 5) in the UK's OER Impact Study funded by JISC. They distinguish between the visible reuse and production of licensed OER that bear the name of the institution, and the invisible reuse by staff and students of digital learning resources in and around the curriculum. The majority of reuse takes place in contexts that are not publicly visible, like the VLE. Much of that reuse is possibly illegal, but the risk may be considered acceptable. Some institutions have put in place structures that accommodate the VLE in copyright terms as an extension of the classroom. Others devolve responsibility to the educational developers or learning technologists supporting the VLE to deal with the issue. However, these teams are usually not resourced to manage this work. Given that the data showed requests for training in this area, such resources are now badly needed. There would be clear scope to work with 
colleagues in our institutional libraries on this issue, and indeed librarians are actively engaged with copyright in e-learning elsewhere (Secker \& Morrison, 2016).

There remains great potential for the use and sharing of OER in institutional VLEs, although this appears to be untapped at present. For example, many academics are astonished to hear of resources such as the UK Open University's OpenLearn philanthropic project (http://www.open.edu/openlearn/), which provides zipped courses and e-books ready to upload to institutional VLEs provided users comply with the Creative Commons licences. In one sense, it can be argued that the password-protected, exclusive nature of the VLE as a 'closed doors' classroom environment is intrinsically opposed to any efforts to engage with open educational practices. In broader terms, a discussion around the use of the VLE and OER, as part of the open education movement, is linked with the broader principle of open educational practice (OEP), as educational culture often militates against the changes in practice required around the large scale sharing and reuse of OER. The OER Impact Study (McGill, Falconer, Littlejohn \& Beetham, 2013, p.9), funded by JISC (the Joint Information Systems Committee), found that:

\begin{abstract}
Although we have evidence of significant practice change, projects are also aware that there is still a fair way to go to make this practice mainstream.
\end{abstract}

\title{
Conclusion
}

In this paper we have presented analysis of the data from the \#VLEIreland staff questionnaire addressing open educational resources and sharing resources through the VLE. Findings are consistent with those of broader studies nationally and internationally: there is generally low level of awareness of OER and how such resources might be found and used. Staff interpreted sharing in a narrow sense, and one not consistent with the open education movement. Sharing was to their immediate colleagues or via the closed environment of the VLE. The VLE is not necessarily the only walled garden being used by staff in their teaching, as other platforms are being used to support closed practices. However, the analysis presented here suggested that this may be due to a combination of concerns which staff have not had time to address or do not have knowledge to address. They seek to protect their work, and that of their students. They lack knowledge of relevant copyright restrictions as well as permissions, they may well be fearful of making mistakes in relation to copyright, and they may also lack time (McAvinia, Ryan \& Moloney, 2018) to establish their own professional development needs in these areas. Harding (2018) points to the role that professional identity and an understanding of learning theory play in designing and implementing pedagogic innovation which moves beyond the use of technologies to maintain the status quo, replicate traditional approaches to teaching and/or to support an increasing administrative load. It is important that, if we seek genuinely to pursue open educational practices and the use and sharing of OER in higher education in Ireland, we begin to support staff in learning about these topics and enabling OER to be used both inside and outside the VLE. 
Irish Journal of Technology Enhanced Learning

Vol 3, Issue 2, 2018

\section{References}

Babson Survey Research Group. (2014). Opening the curriculum: open educational resources in U.S. higher education, 2014. Pearson, U.S. Accessed $5^{\text {th }}$ March, 2018 (http://www.onlinelearningsurvey.com/reports/openingthecurriculum2014.pdf)

Farrelly, T., Raftery, D. \& Harding, N. (2018). Exploring lecturer engagement with the VLE: findings from a multi-college staff survey. [Special Issue, McAvinia \& Risquez]. Irish Journal of Technology Enhanced Learning, 3(2), 11-23.

Harding, N. (2018): The Digital Turn: staff perceptions of the virtual learning environment and the implications for educational developers. [Special Issue, McAvinia and Risquez]. Irish Journal of Technology Enhanced Learning, 3(2), 58-76.

McAvinia, C., Ryan, D. and Moloney, D. (2018): "I don't have the time!" Analysing talk of time in lecturers' use of the VLE. [Special Issue, McAvinia and Risquez]. Irish Journal of Technology Enhanced Learning, 3(2), 35-46.

McGill, L., Falconer, I., Littlejohn, A. \& Beetham, H. (2013b). JISC/HE Academy OER Programme: Phase 3 Synthesis and Evaluation Report. JISC, February 2013. Accessed $8^{\text {th }}$ March 2018.

National Forum (2014). A Roadmap for Enhancement in a Digital World 2015-2017. Dublin: National Forum for the Enhancement of Teaching and Learning. Retrieved from https://www.teachingandlearning.ie/wp-content/uploads/2015/03/Digital-Roadmap-web.pdf

Risquez et al. (2015) Learning resources and open access in Higher Education Institutions in Ireland. National Forum of the Enhancement of Teaching and Learning. Focused Research Report no.1. Dublin: National Forum for the Enhancement of Teaching and Learning. Retrieved from http://www.teachingandlearning.ie/wp-content/uploads/2015/07/Project-1LearningResourcesandOpenAccess-1607.pdf

Secker, J. \& Morrison, C. (2016). Copyright and E-learning: a guide for practitioners. London: Facet Publishing.

UNESCO (2002). Final Report of the Forum on the Impact of Open Courseware for Higher Education in Developing Countries. Retrieved from http://unesdoc.unesco.org/images/0012/001285/128515e.pdf

Weller, M. (2014). The Battle for Open: How openness won and why it doesn't feel like victory. London: Ubiquity Press. Retrieved from https://doi.org/10.5334/bam

Weller, M. (2009). Big OER and little OER. Retrieved from http://nogoodreason.typepad.co.uk/no_good_reason/2009/12/the-politics-of-oer.html

White, D. \& Manton, M. (2011). JISC-funded OER Impact Study. University of Oxford. Retrieved from https://oerknowledgecloud.org/sites/oerknowledgecloud.org/files/OERTheValueOfReuseInH igherEducation.pdf 